\title{
Extractos vegetales de tres especies del género Baccharis inducen la proliferación de células mononucleares humanas
}

\author{
Nelson Alvarenga ${ }^{1 \#}$, Christa Burgos ${ }^{2 \#}$, Iris Villalba ${ }^{2}$, Vivian Giménez ${ }^{2}$, María Mercedes Carpinelli², Pablo \\ H. Sotelo ${ }^{3}$, Andrea Cáceres ${ }^{1}$, *Patricia Langjahr ${ }^{2}$ \\ ${ }^{1}$ Universidad Nacional de Asunción, Facultad de Ciencias Químicas, Dirección de Investigaciones, Departamento de \\ Fitoquímica. Paraguay \\ ${ }^{2}$ Universidad Nacional de Asunción, Instituto de Investigaciones en Ciencias de la Salud, Departamento de \\ Inmunología. Paraguay \\ ${ }^{3}$ Universidad Nacional de Asunción, Facultad de Ciencias Químicas, Dirección de Investigaciones, Departamento de \\ Biotecnología. Paraguay
}

\section{Cómo referenciar este artículo/ How to reference this article:}

Alvarenga $N$, Burgos $C$, Villalba $I$, Giménez $V$, Carpinelli MM, Sotelo PH, Cáceres A, Langjahr P. Extractos vegetales de tres especies del género Baccharis inducen la proliferación de células mononucleares humanas. Mem. Inst. Investig. Cienc. Salud. 2018; 16(2): 12-20

\section{R E S U M E N}

Las plantas de uso en medicina tradicional constituyen una fuente importante de compuestos con actividad inmunomoduladora; entre ellas las especies del género Baccharis, conocidas popularmente como "Jaguareteka'a" en nuestro país, son ampliamente empleadas. En este estudio se evaluó la actividad inmunomoduladora de extractos metanólicos de tres especies del género Baccharis ( $B$. trimera, $B$. notosergilay $B$. punctulata) sobre la proliferación de células mononucleares humanas de sangre periférica. Los extractos de las tres especies estudiadas estimularon la proliferación de las células mononucleares. Específicamente, el extracto de $B$. notosergila estimuló la proliferación celular a todas las concentraciones probadas $(5,10,25$ y $50 \mu \mathrm{g} / \mathrm{mL})$, mientras que los extractos de $B$. trimera y $B$. punctulata mostraron este efecto a 5 y $10 \mu \mathrm{g} / \mathrm{mL}$. Además, por presentar mayor inducción de la proliferación, se realizó un fraccionamiento con diferentes solventes del extracto metanólico de $B$. notosergila y $B$. punctulata. La fracción de acetato de etilo de ambos extractos vegetales aumentó la proliferación celular, sugiriendo que compuestos de polaridad media son los responsables de esta actividad. Estos resultados demuestran que los extractos de $B$. trimera, $B$. notosergila y $B$. punctulata poseen actividad inmunomoduladora sobre células mononucleares humanas y servirán de base a otros estudios para determinar el o los componentes activos de los extractos sobre el sistema inmune.

Palabras clave: inmunomodulación, Baccharis, linfocitos, proliferación celular

\section{Plant extracts of three species of the genus Baccharis induce human mononuclear cells proliferation}

\begin{abstract}
A B S T R A C T
Plants used in traditional medicine are an important source of compounds with immunomodulatory activity. Species of the genus Baccharis, popularly known as "Jaguareteka'a" in our country, are used in folk medicine for the treatment of liver, gastrointestinal, inflammatory and infectious diseases. In this study, we evaluated the immunomodulatory activity of methanolic extracts of three species of the genus Baccharis (B. trimera, B. notosergila and B. punctulata) on the proliferation of human peripheral blood mononuclear cells. Extracts of the three species studied stimulated the proliferation of mononuclear cells. The extract of $B$. notosergila stimulated cell proliferation at all concentrations tested, while extracts of $B$. trimera and $B$. punctulata stimulated at 5 and 10
\end{abstract}


$\mu \mathrm{g} / \mathrm{mL}$. In addition, we carried out a separation with different solvents of the methanolic extract of $B$. notosergila and $B$. punctulata. The ethyl acetate fraction of both plant extracts induced the proliferation of immune cells. These results show that the extracts of $B$. trimera, $B$. notosergila and $B$. punctulata had immunomodulatory activity on human mononuclear cells. Future work will be required to identify the components responsible for the activity on the immune system.

Key words: immunomodulation, Baccharis, lymphocytes, cell proliferation.

\section{INTRODUCCIÓN}

Diversas patologías involucran un inadecuado funcionamiento del sistema inmune, entre ellas pueden citarse a alergias y enfermedades autoinmunes e inflamatorias. Las sustancias inmunomoduladoras son aquellas que tienen la capacidad deregular la respuesta inmune, ya sea estimulándola o suprimiéndola. Las plantas y sus metabolitos constituyen una fuente importante de compuestos inmunomoduladores. Existen diversos productos botánicos con potencial inmunomodulador, identificándose en ellos compuestos activos tales como alcaloides, carbohidratos, diterpenos, flavonoides, isoflavonoides, indoles, fitosteroles, lignanos, polisacáridos, taninos, entre otros ${ }^{(1,2)}$

La mayoría de los agentes inmunomoduladores que actúan induciendo la proliferación de linfocitos, células relevantes de la respuesta inmune, son en general antígeno-miméticos denominados mitógenos o activadores policlonales. Los activadores policlonales estimulan la activación y proliferación de linfocitos uniéndose a sus receptores con independencia de la especificidad, imitando las alteraciones inducidas por el antígeno. Debido a que no poseen las propiedades de antígeno, no estimulan el desarrollo de los linfocitos a células de memoria, por lo que el efecto de estos agentes sobre el sistema inmune se reducirá después de un corto periodo de tiempo ${ }^{(3)}$. Las lectinas son ejemplos de activadores policlonales de linfocitos, una muestra de ellos es el mitógenofitohemaglutinina (PHA), el cual induce principalmente la proliferación de linfocitos $T$ al unirse a residuos de carbohidratos en la membrana celular ${ }^{(3,4)}$.

González et al. ${ }^{(5)}$ reportaron actividad inmunomoduladora en derivados vegetales de Mynthostachys verticillata, demostrando que inducen proliferación de linfocitos. Extractos metanólicos de cuatro ecotipos de Lepidium peruvianum fueron evaluados en cultivos de linfocitos humanos de sangre periférica, demostrando que el ecotipo morado posee propiedades inmunoestimuladoras, desencadenando la activación de linfocitos humanos ${ }^{(6)}$. Así también, Benencia et al. ${ }^{(7)}$ estudiaron el efecto de extractos de Trichilia glabra sobre la respuesta de proliferación linfocitaria inducida por mitógeno, demostrando que tales extractos poseen una actividad inhibitoria.

La familia Asteraceae, conocida antiguamente como Compositae, correspondiente al Orden Asterales Suborden Asteridae, es la familia de angiospermas con mayor diversidad biológica, reuniendo cerca de 25.000 especies repartidas en aproximadamente 1.100 géneros distribuidos en todo el mundo, excepto en la Antártida, hallándose mayoritariamente en zonas tropicales, subtropicales y templadas ${ }^{(8,9)}$.

El género Baccharis es el más rico en especies dentro de la familia Asteraceae, tribu Astereae. Su distribución geográfica es exclusivamente americana, desde el sur de los Estados Unidos de América hasta el extremo austral de Argentina y Chile ${ }^{(10)}$.

Las especies de este género, conocidas popularmente como "Jaguareteka'a" en nuestro país, son por lo general arbustillos que miden de 0,5 a 4 metros de altura, a las que se atribuyen varias propiedades terapéuticas, por lo que son muy empleadas en la medicina popular para el tratamiento de heridas y úlceras, fiebre, enfermedades hepáticas y gastrointestinales, como diuréticos, analgésicos y anti-inflamatorios; así también, para el tratamiento de la diabetes e infecciones bacterianas, helmínticas y fúngicas, entre otros $^{(9,11,12)}$.

Hasta la fecha, más de 150 compuestos han sido aislados e identificados de las especies de este género. En general, los más destacados son los flavonoides, clerodanos y labdanos, aunque también se ha observado con cierta frecuencia la presencia de kauranos, triterpenos, ácidos cumáricos, tricotecenos, sesquiterpenos, entre otros ${ }^{(9,11,12)}$.

Estudios realizados con extractos de Baccharistrimera, mostraron que posee efectos antioxidantes y propiedades anti-hepatotóxicas ${ }^{(13,14)}$. Lozza et al. ${ }^{(15)}$ reportaron actividad anti-inflamatoria de extractos derivados de Baccharis trimera, a la vez demostraron que poseen una actividad inhibitoria sobre la proliferación de linfocitos T inducida por PHA, esta 
actividad fue asociada a una disminución en la viabilidad celular. Cobos et al. ${ }^{(16)}$ demostraron que Baccharis notosergila posee propiedad antimicrobiana con actividad antibacteriana y antifúngica.

Considerando el uso popular de especies del género Baccharis para tratar varias patologías que están relacionadas con el funcionamiento del sistema inmune y el gran potencial de metabolitos secundarios encontrados en ellasse propone evaluar el efecto inmunomodulador sobre células mononucleares humanas de extractos metanólicos de tres especies de este género.

\section{MATERIALES Y MÉTODOS \\ Obtención de extractos vegetales}

Para la realización de este estudio experimental se emplearon extractos vegetales elaborados por el Departamento de Fitoquímica, Facultad de Ciencias Químicas, Universidad Nacional de Asunción (UNA).

Las especies fueron recolectadas e identificadas por investigadores del Departamento de Botánica de la Facultad de Ciencias Químicas, UNA y un ejemplar fue depositado en el Herbario de la Facultad de Ciencias Químicas (FCQ) con fines de indexación. Baccharis trimera fue recolectada del Jardín de Aclimatación de la FCQ, UNA (R. Degen et M. González 4088); Baccharis punctulata en la ciudad de Ñemby, Departamento Central (R. Deguen et G. Delmás, L. Britos, Y. González 4302) y la especie Baccharis notosergila se recolectó de la Ruta Transchaco, Departamento de Presidente Hayes (R. Degen et G. González, L. Britos 4362).

El material vegetal fue secado a la sombra y posteriormente triturado en un molino de cuchillas. Aproximadamente $200 \mathrm{~g}$ de material se puso en contacto con 1,5 L de metanol (J.T. Baker, México D.F., México). La suspensión se sonicó durante 1 hora por 3 veces y el proceso se repitió durante 3 días. Al cabo de ese tiempo el líquido se filtró al vacío empleando papel de filtro (GE Healthcare, Hangzhou, China) y luego se evaporó el solvente empleando un evaporador rotatorio (Boeco, Hamburgo, Alemania).

Los extractos concentrados se resuspendieron en dimetilsulfóxido (DMSO) (Sigma, St Louis, MO, USA) bajo campana de flujo laminar. Estas preparaciones fueron filtradas con un filtro de 0,22 micras, a fin de eliminar microorganismos presentes en el extracto. Los extractos así preparados fueron preservados a $4^{\circ} \mathrm{C}$ hasta el momento de su uso. Para confirmar la adecuada solubilidad de los extractos disueltos en DMSO, se realizó la dilución más alta a utilizarse en los ensayos $(100 \mu \mathrm{g} / \mathrm{mL})$ con medio RPMI y se verificó cualitativamente al microscopio la ausencia de grumos o restos vegetales.

Los extractos crudos fueron extraídos luego con solventes de polaridad creciente. Para ello aproximadamente $1 \mathrm{~g}$ de extracto fue suspendido en agua y luego particionado sucesivamente con hexano (Anedra, Argentina), diclorometano, acetato de etilo (ambos de JT Baker, México D.F., México), y butanol (Merck AG, Darmstadt, Alemania). Los solventes fueron eliminados en un evaporador rotatorio. La fracción acuosa remanente fue liofilizada para eliminar el líquido restante (Labconco Freezone 4.5, Kansas City, MO, USA).

Se emplearon dichas fracciones (acuosa, butanólica, hexánica, diclorometánica y de acetato de etilo) de los extractos vegetales. Las fracciones concentradas se suspendieron en DMSO (Sigma, St Louis, MO, USA) bajo campana de flujo laminar. Estas preparaciones fueron filtradas con un filtro de 0,22 micras. Los extractos fueron preservados a $4^{\circ} \mathrm{C}$ hasta el momento de su uso. Se realizó la dilución a utilizarse $(2 \mathrm{mg} / \mathrm{mL})$ con medio RPMI- 1640 (Sigma, Montana, USA) y se verificó la ausencia de grumos o restos vegetales.

\section{Aislamiento de células mononucleares de sangre periférica humanas}

Las células mononucleares de sangre periférica (CMSP) se aislaron de sangre venosa obtenida de 3 donantes voluntarios adultos, que no refirieron enfermedad, fiebre ni infecciones en los siete días anteriores a la toma de la muestra y firmaron el consentimiento informado correspondiente. Este trabajo fue aprobado por el Comité de Ética de la Facultad de Ciencias Químicas, UNA y por los Comités Científico y de Ética del Instituto de Investigaciones en Ciencias de la Salud, UNA.

Se extrajo una muestra de10 $\mathrm{mL}$ de sangre periférica por punción venosa del antebrazo, de forma estéril. Las muestras de sangre heparinizadas se sometieron a centrifugación sobre gradiente de Ficoll Histopaque $\AA-1077$ (Sigma, St Louis, MO, USA) a 2000 rpm por 20 minutos. Las CMSP se colectaron de la interfase de Ficoll y plasma y se lavaron en medio RPMI. Posteriormente, se realizó el conteo de células con una cámara de Neubauer (Erma, 
Tokyo) y se resuspendieron en medio RPMI-1640 (Sigma, Montana, USA) con 0,3 g/L de Lglutamina (Sigma, Montana, USA) suplementado con $10 \%$ de suero fetal bovino (PAA Laboratories $\mathrm{GmbH}$, Pasching, Austria), 2,4 g/L de ácido N-2-hidroxietilpiperacina- $\mathrm{N}^{\prime}-\mathrm{2}^{\prime}$ etanesulfónico (HEPES) (Gibco, Nueva York, USA), 2,0 g/L de $\mathrm{NaHCO}_{3}($ Merck, Darmstadt, Alemania) y antibióticos (50.000 unidades/L de penicilina y $100 \mu \mathrm{g} / \mathrm{mL}$ de estreptomicina).

\section{Evaluación de la viabilidad celular por el test de exclusión de captación de azul} tripán

La viabilidad de las células se determinó por medio del test de exclusión de captación de azul tripán. Se incubaron $1 \times 10^{6}$ células $/ \mathrm{mL}$ en medio RPMI en una placa de cultivo de 96 pocillos (Iwaki, Japón) por $72 \mathrm{~h}$ a $37^{\circ} \mathrm{C}$ y $5 \%$ de $\mathrm{CO}_{2}$. Las CMSP se trataron con diferentes concentraciones de los extractos metanólicos de las tres especies vegetales por $72 \mathrm{~h}$ a $37^{\circ} \mathrm{C}$ y $5 \% \mathrm{CO}_{2}$.

Posteriormente, las células fueron colectadas e incubadas por 5 minutos con azul tripán (Sigma, St Louis, MO, USA) en proporción 1:1. Se realizó el conteo en una cámara de Neubauer, expresándose los resultados como porcentaje de viabilidad: ( $n^{\circ}$ células vivas $/ \mathrm{n}^{\circ}$ células totales) $\times 100$. Se realizó el ensayo por triplicado.

\section{Ensayo de proliferación celular}

Se incubaron $1 \times 10^{6}$ células $/ \mathrm{mL}$ en medio RPMI en una placa de cultivo de 96 pocillos (Iwaki, Japón) por $72 \mathrm{~h}$ a $37^{\circ} \mathrm{C}$ y $5 \%$ de $\mathrm{CO}_{2}$. Las células fueron tratadas con fitohemaglutinina (PHA) (Sigma, St Louis, MO, USA), como control positivo o con diferentes concentraciones de los extractos vegetales o las fracciones; como control negativo se utilizaron células no estimuladas o tratadas con el vehículo (DMSO).

Se utilizó el método colorimétrico de MTT (3-(4,5-dimetiltiazol-2-il)-2,5-bromuro-difeniltetrazolio) con las modificaciones descritas por Denizot y Lang (17). Al cabo de las $72 \mathrm{~h}$, las células fueron incubadas con $10 \mu \mathrm{L}$ de MTT ( $5 \mathrm{mg} / \mathrm{mL}$ ) (Sigma, USA) por tres horas a $37^{\circ} \mathrm{C}$ y $5 \%$ de $\mathrm{CO}_{2}$. Posteriormente, se agregó $100 \mu \mathrm{L}$ de una solución de 0,04 $\mathrm{N}$ de ácido clorhídrico (Biopack, Argentina) en alcohol isopropílico (Merck Química, Buenos Aires, Argentina) para disolver los cristales de formazán. Se midió la densidad óptica (O.D.) en un lector de ELISA (Awareness Technology Inc, USA) a $570 \mathrm{~nm}$.

Se calculó el Índice de Proliferación (IP) utilizando la siguiente fórmula: O.D. células estimuladas/O.D. células no estimuladas.

\section{Análisis estadístico}

Los datos obtenidos se almacenaron en una planilla y se analizaron estadísticamente mediante la prueba de $t$-test, utilizando el programa estadístico GraphPad Prism 7.0 (La Jolla-California, USA). Se consideraron significativos valores de $p<0,05$. Los valores fueron presentados como media aritmética \pm desviación estándar.

\section{RESULTADOS \\ Citotoxicidad de extractos vegetales del género Baccharis sobre las células mononucleares de sangre periférica humanas}

Al evaluar el efecto del extracto metanólico de $B$. trimera sobre la viabilidad de las CMSP, la concentración de $100 \mu \mathrm{g} / \mathrm{mL}$ del extracto disminuyó el porcentaje de viabilidad con respecto a las células tratadas con el vehículo (DMSO) (Figura 1A). En las células tratadas con el extracto metanólico de $B$. notosergila, se observó un efecto similar; una disminución de la viabilidad de las células tratadas con $100 \mu \mathrm{g} / \mathrm{mL}$ del extracto comparado al control (DMSO) (Figura 1B). En ambos casos, las células tratadas con concentraciones menores (25 y $50 \mu \mathrm{g} / \mathrm{mL}$ ) no presentaron diferencia estadísticamente significativa en comparación con las tratadas con DMSO. Las células tratadas con las concentraciones de 50 y $100 \mu \mathrm{g} / \mathrm{mL}$ del extracto metanólico de $B$. punctulata presentaron una disminución en la viabilidad celular con respecto a las células tratadas con el vehículo (Figura 1C). 
A

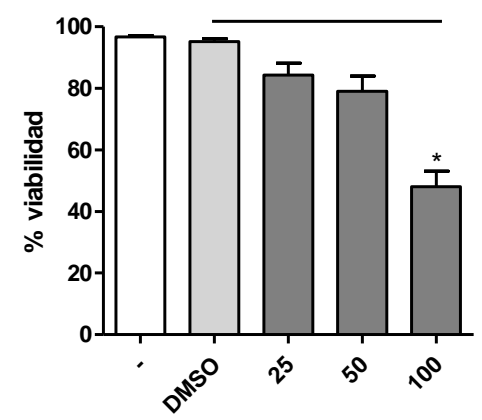

[B. trimera] $(\mu \mathrm{g} / \mathrm{mL})$
B

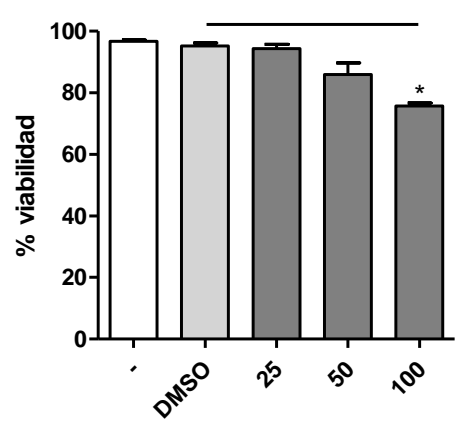

[B. notosergila] $(\mu \mathrm{g} / \mathrm{mL})$

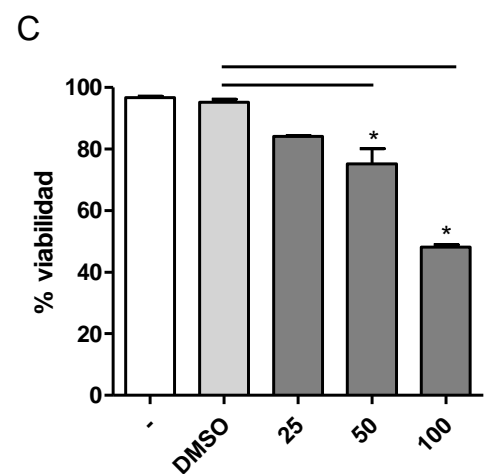

[B. punctulata] $(\mu \mathrm{g} / \mathrm{mL})$

Figura 1. Efecto de extractos metanólicos del género Baccharis sobre la viabilidad de CMSP humanas. Las CMSP fueron cultivadas a una densidad de $1 \times 10^{6}$ células $/ \mathrm{mL}$ y tratadas o no (-) con el vehículo (DMSO) o diferentes concentraciones de extracto metanólico de: A) Baccharis trimera, B) Baccharis notosergila, C) Baccharis punctulata por $72 \mathrm{~h}$ a $370^{\circ} \mathrm{C}$ y $5 \%$ de $\mathrm{CO}_{2}$. Las células tratadas con DMSO (vehículo) se utilizaron como control. El porcentaje de viabilidad fue determinado utilizando el test de exclusión de captación de azul tripán. Promedio \pm desviación estándar. ${ }^{*} p<0,05 . n=3$ donantes.

En base a estos resultados, se decidió utilizar concentraciones de los extractos que no afectan la viabilidad celular para los ensayos de proliferación, menores a $100 \mu \mathrm{g} / \mathrm{mL}$ en el caso de los extractos de $B$. trimera y $B$. notosergila y menores a $50 \mu \mathrm{g} / \mathrm{mL}$ del extracto de B. punctulata.

\section{Evaluación del efecto de los extractos vegetales sobre la proliferación de células mononucleares de sangre periférica humanas}

A fin de evaluar el efecto inmunomodulador de los extractos metanólicos sobre las CMSP, se procedió a realizar un ensayo de proliferación, tal como se describe en materiales y métodos. Se observó que las concentraciones de 5 y $10 \mu \mathrm{g} / \mathrm{mL}$ del extracto de $B$. trimera aumentaron la O.D. con respecto a las células tratadas con el vehículo (DMSO), por lo tanto se produjo una inducción de la proliferación de las células mononucleares del cultivo o efecto inmunoestimulante (Figura 2A). Las células tratadas con las concentraciones de 25 y $50 \mu \mathrm{g} / \mathrm{mL}$ no presentaron diferencias estadísticamente significativas comparadas con las células tratadas con el vehículo.

En las células tratadas con el extracto metanólico de $B$.notosergila se observó un aumento en la O.D. medida con respecto a las tratadas con el DMSO con todas las concentraciones probadas, por lo tanto este extracto estimula la proliferación celular de CMSP a todas las concentraciones testeadas (Figura 2B).

Al igual que $B$. trimera, las concentraciones de 5 y $10 \mu \mathrm{g} / \mathrm{mL}$ del extracto metanólico de $B$. punctulata aumentaron significativamente la proliferación celular en comparación al control (DMSO) (Figura 2C). La concentración correspondiente a $50 \mu \mathrm{g} / \mathrm{mL}$ no fue utilizada, ya que presento una actividad citotóxica sobre las CMSP.

Una vez establecido que los extractos son capaces de inducir la proliferación de CMSP, se procedió a realizar un fraccionamiento químico de los extractos de $B$. punctulata y $B$. notosergila. Se seleccionaron estos extractos por poseer la mayor capacidad de inducir la 
proliferación de CMSP. Ambos extractos fueron separados en cinco fracciones (acuosa, butanólica, hexánica, diclorometánica y de acetato de etilo), para luego realizar los ensayos de proliferación in vitro de CMSP, como fue descrito anteriormente.

A

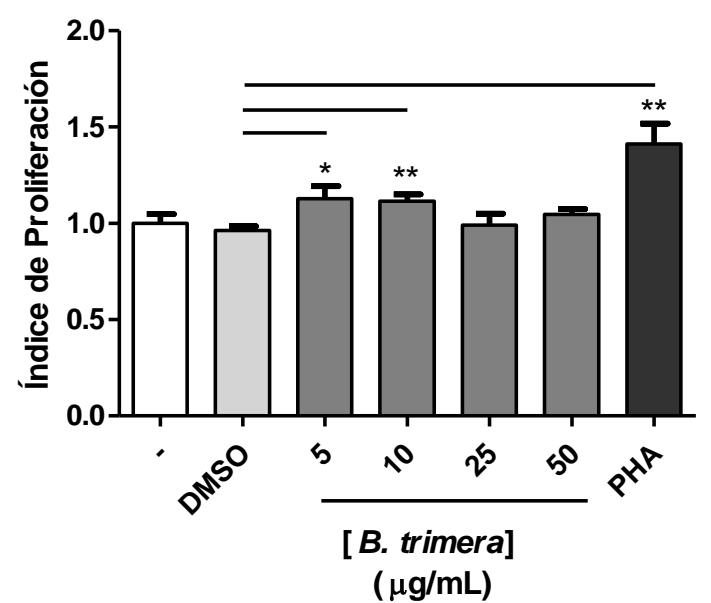

B

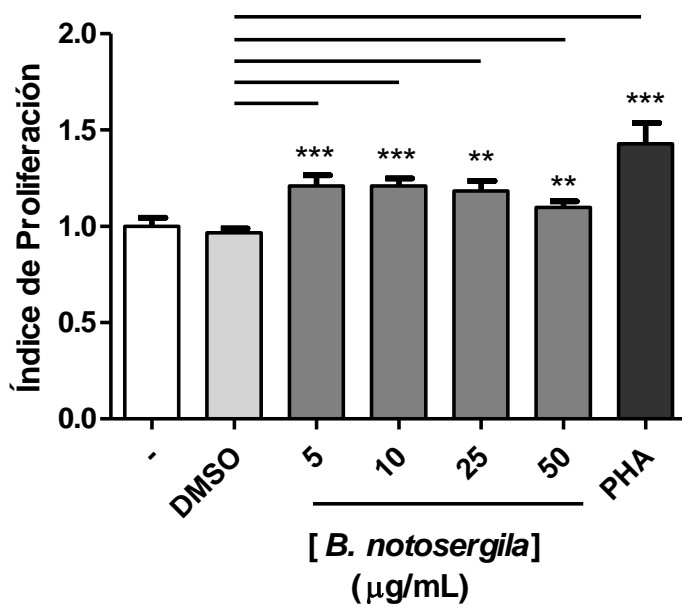

C

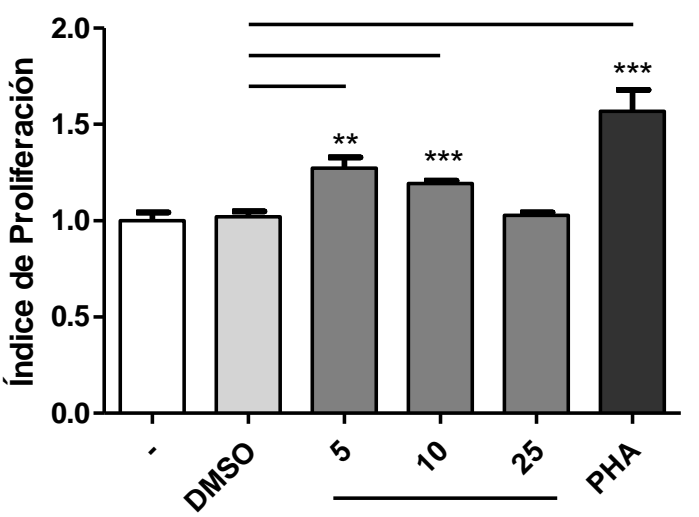

[B. punctulata] $(\mu \mathrm{g} / \mathrm{mL})$

Figura 2. Efecto de extractos metanólicos del género Baccharis sobre la proliferación de CMSP. Las CMSP fueron cultivadas a una densidad de $1 \times 10^{6}$ células $/ \mathrm{mL}$ y tratadas o no (-) con vehículo (DMSO) o diferentes concentraciones del extracto metanólico de: A) Baccharis trimera B) Baccharis notosergila, C) Baccharis punctulata por $72 \mathrm{~h}$ a $37^{\circ} \mathrm{C}$ y $5 \%$ de $\mathrm{CO}_{2}$. Las células tratadas con PHA se utilizaron como control positivo del ensayo.La proliferación celular fue determinada por el método colorimétrico de $\mathrm{MTT}$, expresado como índice de proliferación. ${ }^{*} \mathrm{p}<0,05 ; * * \mathrm{p}<0,01$; $* * * \mathrm{p}<0,001 . \mathrm{n}=3$ donantes.

Al tratar las células CMSP con las fracciones de cada extracto pudo observarse que la fracción de acetato de etilo presentó una inducción de la proliferación celular, lo cual sugiere que el o los componentes activos presentes en esta fracción podrían inducir la proliferación de CMSP (Figura 3A, Figura 3B). 
A

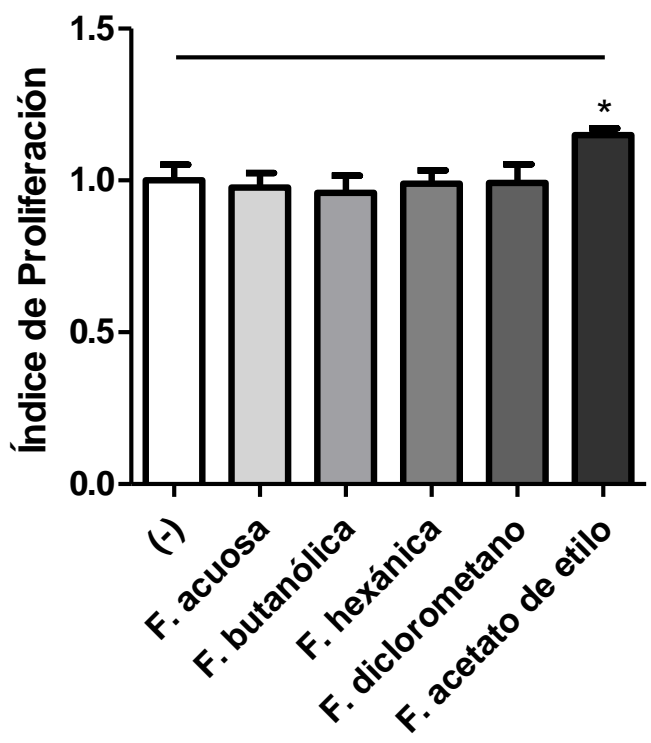

B

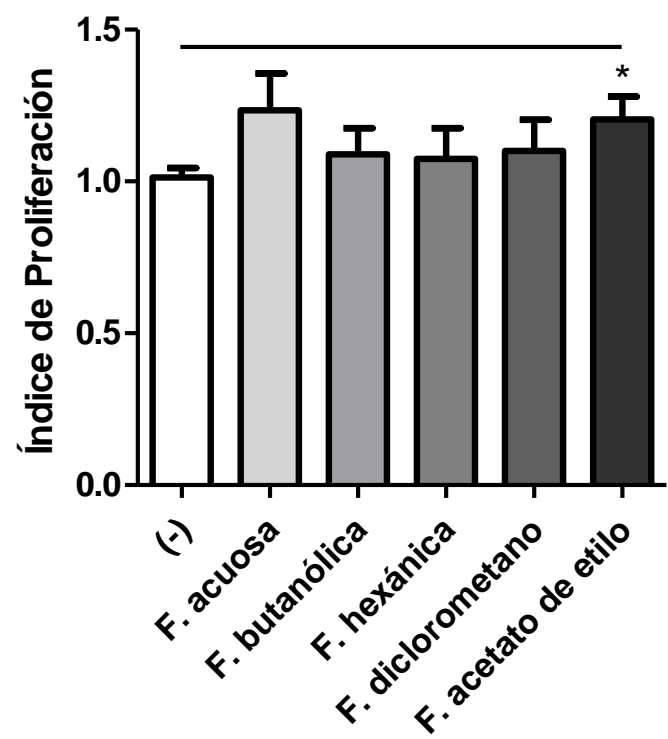

Figura 3: Efecto de las fracciones de extractos metanólicos de Baccharis pucntulata y Baccharis notosergila sobre la proliferación de CMSP. Las CMSP fueron cultivadas a una densidad de $1 \times 10^{6}$ células $/ \mathrm{mL}$ y tratadas o no $(-)$ con $10 \mu \mathrm{g} / \mathrm{mL}$ de las fracciones del extracto metanólico de: A) Baccharis notosergila o B) Baccharis punctulata por $72 \mathrm{~h}$ a $37^{\circ} \mathrm{C}$ y $5 \%$ de $\mathrm{CO}_{2}$. La proliferación celular fue determinada por el método colorimétrico de MTT, expresado como índice de proliferación. ${ }^{*} \mathrm{p}<0,05 . \mathrm{n}=3$ donantes.

\section{DISCUSIÓN}

En los últimos años, la búsqueda e identificación de metabolitos de plantas con actividad inmunomoduladora se ha incrementado debido al potencial que presentan en el tratamiento y prevención de enfermedades ${ }^{(18)}$. Existen reportes de numerosas especies vegetales que han demostrado capacidad para modular el sistema inmune, con una variedad de compuestos responsables de dicho efecto como polisacáridos, lectinas, péptidos, flavonoides, taninos y otros más ${ }^{(18,19)}$. Una evaluación del efecto de productos vegetales sobre células del sistema inmune es necesaria para reconocer el potencial que presentan en el manejo de trastornos inflamatorios, tumores, infecciones y otros desórdenes inmunitarios ${ }^{(20)}$.

Las plantas del género Baccharis tienen un amplio uso en la medicina popular, por lo que extractos y compuestos obtenidos de algunas especies han sido investigados en la búsqueda de actividades biológicas ${ }^{(11)}$. En este trabajo, se evaluaron los extractos metanólicos de las especies Baccharis trimera, Baccharis notosergila y Baccharis punctulata en cuanto a su capacidad de modular la respuesta inmune, específicamente la proliferación de CMSP humanas in vitro.

Las concentraciones menores a $100 \mu \mathrm{g} / \mathrm{mL}$ utilizadas de los extractos de $B$. trimera y $B$. notosergila no mostraron cambios en la viabilidad de las CMSP, mientras que el extracto de B. punctulata disminuyó la viabilidad de las células tratadas con 50 y $100 \mu \mathrm{g} / \mathrm{mL}$, no así a $25 \mu \mathrm{g} / \mathrm{mL}$. Se ha reportado la presencia de tricotecenos macrocíclicos en numerosas especies de plantas del género Baccharis, los cuales presentan alta toxicidad sobre células eucariotas ${ }^{(21)}$. Estos compuestos podrían ser los responsables de la disminución de la viabilidad celular al aumentar las concentraciones de extractos. El efecto citotóxico de los extractos sobre las CMSP es interesante considerando un posible efecto inmunosupresor a través de la inducción de muerte de linfocitos, mecanismo de acción de diversos inmunosupresores utilizados actualmente como los $\operatorname{corticoides}^{(22,23)}$.

Los extractos de las tres especies estudiadas fueron capaces de inducir la proliferación de CMSP. El extracto metanólico de $B$. notosergila estimuló la proliferación celular a todas las concentraciones ensayadas. Los extractos de las especies $B$. trimera y $B$. punctulata indujeron la proliferación de CMSP a 5 y $10 \mu \mathrm{g} / \mathrm{mL}$. El efecto disminuyó con el aumento de la concentración de extractos sobre los cultivos de CMSP. Estos ensayos mostraron que a bajas concentraciones los extractos inducen la proliferación de CMSP, indicando además que no presentan efecto citotóxico sobre las células a estas concentraciones. 
El principal componente celular presente en el cultivo de CMSP son los linfocitos. Ha sido reportado que los linfocitos pueden ser activados y proliferar en presencia de extractos vegetales ${ }^{(24)}$. El mecanismo por el cual se induce la proliferación no está esclarecido, podría ser debido a la interacción de componentes del extracto con moléculas de la superficie celular o receptores de factores de crecimiento. Este efecto podría deberse a la presencia de lectinas que se unan a carbohidratos del complejo del receptor de linfocitos T (TCR) que induzcan proliferación, similar al mecanismo de inducción de la proliferación del $\mathrm{PHA}^{(25)}$. Además, se ha sugerido que otros componentes como alcaloides o polifenoles pueden ser responsables de este efecto. Otros mecanismos de acción propuestos son la interferencia con la señalización celular o producción de citoquinas ${ }^{(26)}$. Se ha reportado que $B$. trimera disminuye la proliferación inducida por PHA de linfocitos ${ }^{(15)}$, sin embargo en este trabajo se evaluó el efecto sobre la proliferación no inducida por PHA de células mononucleares, observándose un aumento en la proliferación.

Los extractos de $B$. punctulata y $B$. notosergila se sometieron a fraccionamiento con solventes de diferente polaridad. La fracción de acetato de etilo, tanto del extracto de $B$. punctulata como $B$. notosegila aumentó la proliferación celular, sugiriendo que compuestos de polaridad media son los responsables de esta actividad.

La estimulación de la respuesta inmune por agentes inmunomodulares se utiliza como inmunoterapia en patologías tales como cáncer e inmunodeficiencias ${ }^{(27)}$. Los resultados observados, demuestran que estos extractos poseen actividad potenciadora sobre las células inmunes in vitro, sugiriendo que podrían aislarse compuestos con esta actividad a ser utilizados en el tratamiento de estas enfermedades. Considerando que sólo se ha identificado la fracción activa, no se puede afirmar si el responsable del efecto observado es un solo compuesto o varios, que actúan en forma sinérgica. Estos resultados sirven de base para futuros estudios de identificación del o los compuestos responsables de la actividad.

Considerando que en este trabajo se utilizó como modelo de ensayo células humanas in vitro; sería importante realizar estudios en modelos animales a fin de analizar el efecto estas especies de Baccharis y sus fracciones sobre el sistema inmune en un contexto fisiológico. Sin embargo, cabe resaltar que pueden presentarse diferencias entre el efecto observado en modelos murinos y en humanos ${ }^{(28)}$. En este contexto, es importante notar que este trabajo aporta información sobre el efecto en células humanas provenientes de donantes sanos.

Estos resultados, en conjunto, demuestran que los extractos metanólicos de Baccharis trimera, Baccharis notosergila y Baccharis punctulata presentan actividad inmunomoduladora sobre las CMSP humanas y que estas especies poseen potencial como fuente de compuestos con actividad sobre el sistema inmune.

\section{REFERENCIAS BIBLIOGRAFICAS}

1. Jantan I, Ahmad W and Bukhari SNA. Plantderived immunomodulators: an insight on their preclinical evaluation and clinical trials. Front. Plant Sci. 2015; 6:655.

2. Patwardhan B, Gautam M. Botanical immunodrugs: Scope and opportunities. Drug Discov Today. 2005;10(7):495-502.

3. Yeap SK, Rahman MB, Alitheen NB, Ho WY, Omar AR, Beh BK, et al. Evaluation of immunomodulatory effect: Selection of the correct targets for immunostimulation study. Am J Immunol. 2011;7(2):17-23.

4. Nowell P. Phytohemagglutinin: An Initiator of Mitosis in Cultures of Normal Human Leukocytes. Cancer Res. 1960;20(4):462-6.

5. González ML, Cariddi LN, Ybarra F, Isola MC, Demo MS, Sabini $\mathrm{L}$, et al. Minthostachys verticillata on human lymphocytes and basophils. Rev Alerg Mex. 2005;52(3):105-12.

6. Alzamora L, Galvan P, Alvarez E, Torres D, Colona $E$, Aliaga $M$, et al. Producción de IFN $-\mathrm{Y}$ en cultivos de linfocitos humanos por efecto de los extractos metanólicos de cuatro ecotipos de Lepidium peruvianum, Chacón (Brassicaceae). Rev peru biol. 2007;13(3):207-9.

7. Benencia $F$, Courrèges $M C$, Coulombié FC. In vivo and in vitro immunomodulatory activities of Trichilia glabra aqueous leaf extracts. J Ethnopharmacol. 2000;69 (3): 199-205.

8. Del Vitto L, Petenatti E. Asteráceas de importancia económica y ambiental. Primera parte. Sinopsis morfológica y taxonómica, importancia ecológica y plantas de interés industrial. Multequina. 2009;18:87-115.

9. Gonzaga L, Costa MI, Pizzolatti MG. Género Baccharis (Asteraceae): Aspectos químicos, económicos e biológicos. Quim Nova. 2005;28(1):85-94.

10. Giuliano D. Clasificación infragenérica de las especies argentinas de Baccharis (Asteraceae, Astereae). Darwiniana. 2001;39(1-2):131-54

11. Campos FR, Bressan J, Godoy V, Zuccolotto T, Silva LE da, Bonancio L. 
Baccharis (Asteracea): Chemical Constituents and Biological Activities. Chem Biodivers. 2016;13:1-17.

12. Abad M, Bermejo P. Baccharis (Compositae): a review update. Arkivoc. 2007; (7):76-96.

13. De Las Heras $B$, Slowing $K$, Benedí J, Carretero E, Ortega T, Toledo C, et al. Antiinflammatory and antioxidant activity of plants used in traditional medicine in Ecuador. J Ethnopharmacol. $1998 ; 61(2): 161-6$.

14. Soicke $H$, Leng-Peschlow $E$. Characterisation of flavonoids from Baccharis trimera and their antihepatotoxic properties. Planta Med. 1987;53(1):37-9.

15. Lozza $E$, Lunardelli $A$, Caberlon $E$, de Oliveira CB, Santos RCV, Biolchi V, et al. Anti-inflammatory and Immunomodulatory Effects of Baccharis trimera Aqueous Extract on Induced Pleurisy in Rats and Lymphoproliferation In Vitro. Inflammation. 2009;32(6):419-25.

16. Cobos $M$, Rodríguez J, Oliva $M$, Demo $M$, Faillaci S, Zygadio J. Composition and antimicrobial activity of the essential oil of Baccharis notosergila. Planta Med. 2001;67(1):81-3.

17. Denizot F, Lang R. Rapid colorimetric assay for cell growth and survival. Modifications to the tetrazolium dye procedure giving improved sensitivity and reliability. J Immunol Methods. 1986;89(2):271-7.

18. Shukla S, Bajpai VK, Kim M. Plants as potential sources of natural immunomodulators. Rev Environ Sci Biotechnol. 2014;13(1):17-33.

19. Shukla S, Mehta A, Mehta P, Vyas SP, Shivaprasad HN. In vivo immunomodulatory activities of the aqueous extract of bonduc nut Caesalpinia bonducella seeds. Pharm Biol. $2010 ; 48(2): 227-30$.
20. Nworu CS, Temchura V, Okoye FBC, Akah $\mathrm{P}$ a, Esimone $\mathrm{CO}$, Uberla $\mathrm{K}$. Activation of murine lymphocytes and modulation of macrophage functions by fractions of Alchornea cordifolia (Euphorbiaceae) leaf extract. Immunopharmacol Immunotoxicol. 2010;32(1):28-36.

21. Mongelli E, Desmarchelier C, Talou JR, Coussio J, Ciccia G. In vitro antioxidant and cytotoxic activity of extracts of Baccharis coridifolia DC. J Ethnopharmacol. $1997 ; 58(3): 157-63$.

22. Liberman AC, Druker J, Refojo D, Arzt E. Molecular mechanisms of action of some immunosuppressive drugs. Medicina (B Aires). 2008;68(6):455-64.

23. Olnes $M J$, Kotliarov $Y$, Biancotto $A$, Cheung $F$, Chen J, Shi $R$, et al. Effects of systemically administered hydrocortisone on the human immunome. Sci Rep. 2015; 14(6):23002.

24. Odette KM, Simplice MR, Christopher T, Marcel $Y$, Jules-roger K. Evaluation of the immunomodulatory activity of the methanol extract of Alchemilla kiwuensis Engl. Int J Biol Pharm Res. 2013;4(5):34955.

25. Chrispeels MJ, Raikhel N V. Lectins, lectin genes, and their role in plant defense. Plant Cell. 1991;3(1):1-9.

26. Punturee $K$, Kasinrerk W, Wild $C P$, Vinitketkumnuen $U$. Immunomodulatory effects of Thai medicinal plants on the mitogenstimulated proliferation of human peripheral blood mononuclear cells in vitro. Chiang Mai Med J. 2005;44(1):1-12.

27. Rama Bhat P. A Review on Immunomodulatory Effects of Plant Extracts. Virol Immunol J. 2018; 2(6): 000167.

28. Perlman RL. Mouse models of human disease. An evolutionary perspective. Evol Med Public Health. 2016; (1):170-6. 